\title{
A prestação obrigacional do cirurgião plástico como obrigação de resultado: sistematização e análise crítica dos fundamentos
}

\author{
The legal obligation of the plastic surgeon as a result obligation: \\ systematization and critical analysis of the fundamentals
}

\author{
Sergio Domingos Pittelli
}

Pittelli SD. A prestação obrigacional do cirurgião plástico como obrigação de resultado: sistematização e análise crítica dos fundamentos. Saúde, Ética \& Justiça. 2011;16(2):93-102.

RESUMO: O autor aborda e sistematiza os argumentos favoráveis à consignação de obrigação de resultado à obrigação jurídica do cirurgião plástico. Três grupos de fundamentos são identificados e discutidos: histórico, relativo à incidência da álea e jurídico.

DESCRITORES: Cirurgia plástica; Responsabilidade civil; Doença iatrogênica.

U ma das questões mais momentosas no âmbito do Direito Médico é a relativa à natureza da obrigação do profissional. Como é sabido, a obrigação jurídica pode ser de meio (ou meios, segundo preferem alguns) ou de resultado. Pela primeira, obriga-se o prestador de serviço apenas e tão somente a valer-se, de forma adequada, de todos os meios disponíveis ao seu alcance para desincumbirse de seu encargo. O resultado final da ação do profissional, nessa circunstância, não implica em nenhuma conseqüência jurídica para ele. Já a obrigação de resultado, como o próprio nome diz, implica na justa expectativa de que determinada meta seja alcançada, sob pena de, se não realizada, acarretar responsabilidade para 0 prestador. Profissões tais como medicina (e demais áreas da saúde) e advocacia inscrevem-se no conjunto das atividades em que predomina a natureza de meios da obrigação. Utilizamos propositadamente o termo "predomina" porque em todas elas sempre há situações em que a obrigação é efetivamente de resultado. Um exemplo paradigmático para o advogado, a propósito, é o respeito aos prazos processuais. Já o engenheiro, por exemplo, obrigase a resultado certo e esperado.

Médico, mestre em ciências neurológicas pelo Departamento de Neurologia da FMUSP e doutor em ciências pelo Departamento de Medicina Legal da FMUSP. Advogado especializado na área da saúde.

Endereço para correspondencia: Depto de Medicina Legal, Ética Médica e Medicina Social e do Trabalho da Faculdade de Medicina da Universidade de São Paulo. Av. Dr. Arnaldo, 455, Cerqueira Cesar. CEP: 01246-903. São paulo,SP. 
No que respeita à medicina, a questão relativa à dicotomia em apreço tem seu contorno mais polêmico relacionado à ubicação da cirurgia plástica estética no conjunto das atividades cuja natureza da obrigação é de resultado, a ponto de o combate a tal atribuição constituir-se verdadeira "cruzada" da especialidade.

Podemos dizer que a caracterização da prestação obrigacional do cirurgião plástico pode ser analisada sob três aspectos diversos: um de natureza histórica, outro relativo ao raciocínio subjacente à atribuição da álea, expressa por um discurso característico, e um terceiro, de natureza jurídica.

Veremos cada um deles a seguir mas, antes, é necessário discorrer sobre a história do próprio conceito de obrigação de resultado.

\section{Histórico do conceito de obrigação de resultado}

Posto isso, aduzimos que a literatura nos remete a Demogue, grande jurista francês da virada do século XIX para o XX, criador do conceito, e é interessante notar que, no seu nascedouro, a questão não guardava a menor relação com a medicina. Como é sabido, o século XIX caracterizouse por mudanças importantes no Direito, devidas basicamente à revolução industrial. $\mathrm{O}$ aparecimento das grandes fábricas e suas linhas de produção, dos transportes de massa e a urbanização acelerada com aumento da densidade populacional das cidades e conseqüente aparecimento dos problemas de vizinhança geraram a necessidade da construção teórica e jurisprudencial (inicialmente) e depois legislativa, de instrumental jurídico que protegesse não apenas a massa trabalhadora, mas mesmo o usuário de serviços tais como o transporte de massa. E foi exatamente estudando esse tema que Demogue criou o conceito: as empresas férreas e de navegação estariam obrigadas a entregar a mercadoria ou pessoa sã e salva no ponto de destino. Tratava-se, segundo o autor citado, de obrigação de resultado. É relevantíssimo para esta discussão explicitar o critério utilizado por Demogue para diferenciar as situações em que as obrigações seriam de meios ou de resultado: a ocorrência de álea. Estando presentes fatores aleatórios, a obrigação seria de meios, do contrário, de resultado.

Aqui impõe-se um parêntese para deixar registrado que álea não deve ser confundida com dois outros conceitos também muito importantes: caso fortuito e força maior. Não é o momento de dissertar aprofundadamente sobre a diferença, mas apenas para exemplificar, um raio que cai sobre alguém (embora, em sentido amplo, não deixe de ser "aleatório") tem natureza de caso fortuito, pois queda de raios não faz parte da vida natural das pessoas, não se trata de um fenômeno intrínseco à natureza da pessoa ou da vida humana. Para continuarmos, basta deixar registrado que, enquanto qualquer situação da vida está sujeita ao caso fortuito (e força maior), conforme o exemplo acima, a álea acomete apenas parte das atividades humanas e da natureza. Neste sentido estrito, a palavra álea refere-se à qualidade de determinados processos cujos elementos não são de todo controláveis ou previsíveis, havendo, no seu transcurso, razoável grau de imponderabilidade "normal", sem que seja necessário apelar para fatos extras e/ou excepcionais, tal como no caso fortuito. Em outras palavras, a imponderabilidade (álea) é parte intrínseca do processo e verifica-se durante todo o seu devir.

No caso dos transportes de massa, utilizado por Demogue, entendeu ele que não existe álea. Assim sendo, apenas a ocorrência de caso fortuito ou força maior eximiria a empresa de responsabilidade (essa afirmação deve ser entendida com reserva, se levarmos em conta a teoria da responsabilidade objetiva, que não será objeto deste texto).

Feitos estes esclarecimentos, vejamos agora os fundamentos a que se refere o título deste artigo, iniciando pelo elemento histórico, para que se entenda como o conceito foi transferido de fenômenos sociais tais como o transporte de massa para a medicina.

\section{A origem histórica do entendimento da natureza obrigacional do cirurgião plástico como obrigação de resultado}

A origem remota da questão encontra-se na postura da igreja católica medieval com referência à intocabilidade do corpo humano. Neste sentido, é elucidativa a referência à figura de Gaspare Tagliacozzi, cirurgião italiano do século XVI (15451599), espécie de "tataravô" dos cirurgiões plásticos atuais, que se notabilizou por operar mutilados, à época, pela guerra, sífilis e lepra. Seu final foi trágico: consideradas heresias suas cirurgias, porque mexiam com o corpo humano, foi julgado e executado pela inquisição italiana. Outro episódio igualmente elucidativo é o referente ao tratamento da fenda palatina. Em 1764 (portanto, século XVIII, em pleno iluminismo) um cirurgião francês chamado Le Mounier relatou o primeiro tratamento de fenda palatina. Na mesma época, cirurgiões começaram 
Pittelli SD. A prestação obrigacional do cirurgião plástico como obrigação de resultado.

a aplicar técnicas para correção de vários defeitos faciais. Pressionada pela Igreja, entretanto, a Faculdade de Medicina de Paris suspendeu tais práticas.

A história da cirurgia plástica no final do século XIX e século $X X$, segundo Pereira ${ }^{1}$, pode ser dividida em três fases: rejeição, aceitação com reservas e aceitação plena.

$\mathrm{Na}$ primeira, a cirurgia exclusivamente estética era por si só considerada ilícita e o ato reprovável. Havia forte tendência dos tribunais a condenar o cirurgião e o exemplo paradigmático é o julgamento do caso Suzana Geofre versus Dujarrier, pelo Tribunal do Sena, em 1926. A sentença baseou-se em dois argumentos: o primeiro deles referente ao dano causado pelo erro do profissional, assimilável plenamente ao conceito de "erro médico". O segundo, no qual reside a importância para este texto, refere-se ao entendimento do Tribunal a respeito da sacralidade do corpo humano (termo presente na sentença) e que ao cirurgião não era dado o poder de mexer no corpo humano são. A relação dessa concepção com a concepção católica acima exposta é óbvia.

A segunda fase caracterizou-se por impor restrições apenas aos procedimentos estéticos estritamente embelezadores, que tivessem a finalidade, por exemplo, de agir sobre as alterações devidas ao envelhecimento. A cirurgia estética em si, quando aplicada a defeitos congênitos ou adquiridos, passou a ser considerada lícita, mesmo levando-se em conta que sua motivação fosse a vaidade. Considerava-se que ela poderia cumprir a função de melhorar a qualidade de vida de pessoas, inclusive com efeitos psicológicos, ao minimizar ou eliminar imperfeições anatômicas. 0 paradigma, no caso, é a sentença do Tribunal do Sena em 25 de fevereiro de 1929, que levou em conta tais elementos.

Finalmente, a terceira fase caracterizase pelo entendimento da plena liceidade da cirurgia estética estritamente embelezadora. Não se imputa mais ao cirurgião a pecha moral de violar a sacralidade do corpo (primeira fase) ou fomentar a vaidade e futilidade humanas (segunda fase). A "alforria", entretanto, não foi completa; restaram, a nosso ver, duas "seqüelas" a saber: a maior severidade com que os Tribunais julgam os cirurgiões plásticos e a inscrição do procedimento no grupo da obrigação de resultado. As duas circunstâncias podem ser facilmente constatadas da leitura da literatura especializada. Os exemplos nesse sentido são numerosíssimos. Citaremos apenas três, por questões de economia e espaço. Neste sentido, assim se expressa Dias² (p. 288):
“Aspecto eminentemente moderno da
medicina é a cirurgia estética. Esta aplicação
da ciência não tem sido encarada com muita
benevolência pelos tribunais, naturalmente
impressionados pela feição menos nobre da
cirurgia estética posta a serviço da vaidade fútil
ou dos até hoje inexeqüíveis processos de
rejuvenescimento...";
Castro ${ }^{3}$ (p. 149):
"Toda esta carga pejorativa com que era vista a
cirurgia estética impregnou a jurisprudência, que
passou a considerar o dano causado nessas
operações, pela sua só produção, imputável ao
médico"; Couto Filho e Souza (4) (p. 18): "Impor
à cirurgia plástica estética a pecha de obrigação
de resultado é, ao nosso ver, grande preconceito
existente em tempos longínquos....".
Os textos transcritos deixam clara a relação entre as idéias relativas à sacralidade e intocabilidade do corpo humano e os conceitos que envolveram a cirurgia plástica estética em suas diversas fases históricas.

\section{A concepção equivocada a respeito da relação entre álea e os passos do procedimento cirúrgico estético}

O segundo mecanismo citado acima diz respeito ao que podemos denominar de "raciocínio errôneo" característico dos juristas ao se representarem verbal e/ou mentalmente o conceito de álea quando aplicado ao tema. Mais uma vez apelaremos para algumas citações, deixando registrado também aqui que o número disponível é bem mais numeroso do que as poucas de que nos valeremos. Nas transcrições que seguem, alguns trechos estão sublinhados por nós. O motivo será explicado em seguida. Neste sentido, Lalou apud Giostri (p.87): "Sempre que o resultado buscado pelas partes for aleatório, a correspondente obrigação será uma simples obrigação geral de prudência e diligência"; Pereira ${ }^{1}$ (p.151): "Aobrigação do médico, que é chamado a atender a um cliente, não constitui (salvo na cirurgia plástica estética) uma obrigação de resultado, porém uma obrigação de meios. Ele não assume o compromisso de curar o doente (o que seria contra a lógica dos fatos)..."; Rodrigues $^{6}$ (p.17): "Nalguns negócios o devedor apenas promete envidar esforços para alcançar um resultado, sem se vincular a obtê-lo. É o caso do médico que se propõe a tratar de um doente, sem poder garantir que o curará"; finalmente, Kfoury 
Pittelli SD. A prestação obrigacional do cirurgião plástico como obrigação de resultado.

Neto $^{7},(\text { p.178) })^{(1)}$

"A regra geral dita que o médico não pode obrigar-se, no desempenho de sua atividade profissional, aobterresultadodeterminadoacerca da cura do doente e assumir o compromisso de reabilitar sua saúde"; "Conseqüentemente, no que se refere às demais especialidades médicas que tenham por fim a cura direta do paciente (cardiologia, ..... ), o médico especialista vinculase a uma obrigação de meios..."; "Há uma série de especialidades cuja finalidade específica não é a cura direta do enfermo; constituem antes meios auxiliares para se alcançar tal objetivo. Os médicos especialistas em análises clínicas, bioquímica e radiologia, por exemplo, assumem obrigação de resultado, sem que o exame, em si mesmo, conduza à cura".

Todas as transcrições acima (e inúmeras outras de que poderíamos lançar mão) revelam a concepção de que, para os autores, em geral, a álea está associada exclusivamente ao resultado final, entenda-se cura, do processo. Não por acaso, todas as palavras acima grifadas são "resultado" ou "cura" ou ainda a expressão equivalente "reabilitar a saúde". As pessoas não se dão conta de que a álea associada ao resultado final ou cura é apenas e tão somente reflexo da álea carreada pelos processos intermediários, todos de natureza biológica: resposta imunológica, resposta aos fármacos, performance dos mecanismos fisiológicos e fisiopatológicos e, "last but not least", os mecanismos de inflamação e reparo, ou seja, cicatrização, fenômeno biológico por excelência ligado à atividade do cirurgião plástico. Ao fazer o "curto-circuito" mental de associar a álea diretamente ao resultado final, cura, os autores, por um lado ignoram toda a imprevisibilidade existente nos processos biológicos eles mesmos, e, por outro lado, como a cirurgia exclusivamente estética não "cura", incorrem no erro de entender que, em não havendo cura, não há que se falar em álea e a correspondente obrigação passa a ser de resultado.

Queremos ressaltar que a concepção de que a álea se verifica já nos processos intermediários e não apenas no resultado final já se encontra presente na literatura pertinente, mas os autores parecem não ter se dado conta da importância da diferenciação que expusemos acima e de suas implicações verdadeiramente epistemológicas e de convencimento.

Expressam-se claramente neste sentido, Andorno $^{8}$, Aguiar Jr. ${ }^{9,10}$, Forster ${ }^{21}$, Ometto ${ }^{12}$ e Giostri $^{5}$, entre outros. É conhecida e amplamente citada a posição de Andorno ${ }^{8}$, autor que inclusive revela ter mudado sua opinião original a respeito. Fundamenta sua posição nas idéias do jurista e professor francês François Chabas, segundo quem, de acordo com últimas conclusões da ciência médica, o comportamento da pele humana, de fundamental importância na cirurgia plástica, é imprevisível, havendo também um caráter aleatório em qualquer intervenção.

Em nosso meio, Aguiar Jr. ${ }^{9,10}$, também se fundamenta na álea associada à reação do organismo, presente em toda cirurgia. Rechaça explicitamente o argumento de que o cirurgião plástico se obriga ao resultado mediante promessa, afirmando que isso não define a natureza da obrigação "que continua sendo a de prestar um serviço que traz consigo o risco".

Forster ${ }^{11}$ observa que a cirurgia plástica ocorre no mesmo meio onde se dão os demais atos médicos, o ambiente biológico do corpo humano, com sua dinâmica própria caracterizada pela instabilidade e imprevisibilidade. Ressalta que do mesmo modo como não é certo o resultado numa cirurgia gástrica, não o é no procedimento estético e que se fosse correto exigi-lo aqui, sê-lo-ia também para todo e qualquer ato médico. Argumenta que a questão da incerteza relativa aos fatos biológicos deve merecer mais ênfase na análise da natureza jurídica da obrigação do médico na cirurgia estética.

Ometto $^{12}$ destaca que há várias questões que não estão sob o domínio do cirurgião plástico, tais como a evolução do processo de cicatrização, que depende de fatores individuais como espessura e textura da pele, além de influências hereditárias e hormonais. Cita ainda outros elementos inerentes às cirurgias em geral e à anestesia, afirmando, com referência a esta última que "não se sabe se o indivíduo entrará em choque com a medicação, se haverá parada cardíaca, embolia pulmonar, por exemplo". Uma questão interessante lembrada por esta autora é a da assimetria, tanto anatômica quanto funcional, dos organismos em geral e do corpo humano. A implicação do fato é que também os fenômenos de reparação (nos quais se inclui a cicatrização) podem se dar de modo assimétrico

\footnotetext{
(1) De notar que este autor não encampa a idéia de que a obrigação do cirurgião plástico é de resultado, mas pelos textos transcritos pode-se concluir que incorre na mesma falha de raciocínio que estamos tentando explicitar.
} 
devido exclusivamente à álea.

Kfouri $\mathrm{Neto}^{7}$ expõe seu entendimento de que na cirurgia plástica podem ocorrer fatores imprevisíveis e imponderáveis, subjacentes à saúde do paciente, que o médico não conhece nem podia conhecer, "mesmo agindo com diligência e acuidade". Conclui que seu objetivo pode frustrarse pela superveniência de causas que ele não podia prever nem evitar.

As diferentes afirmações convergem todas para o sentido acima exposto, relativo ao processo e não ao resultado final, cura: que o comportamento da pele humana é imprevisível, havendo um componente aleatório em toda intervenção sobre ela. Que a cirurgia plástica ocorre no mesmo meio onde se dão os demais atos médicos, o ambiente biológico do corpo humano, com sua dinâmica própria caracterizada pela instabilidade e imprevisibilidade e que a questão da incerteza relativa aos fatos biológicos deve merecer mas ênfase na análise da natureza jurídica da obrigação do médico na cirurgia estética. Citam ainda influências hormonais e hereditárias e até a assimetria natural entre os dimídios corporais, lembrando que esta assimetria pode se verificar também no fenômeno da cicatrização.

Concluímos que, não obstante já existirem manifestações a favor da presença da álea nos processos intermediários (e não apenas no resultado final, "cura"), a importância de realçar o erro de raciocínio em que incorrem os defensores da obrigação de resultado está em que, em termos de convencimento, é muito mais eficaz demonstrar a falácia de um argumento, do que contrapor-lhe outro, simplesmente.

\section{Argumentos de natureza jurídica}

Este terceiro grupo é constituído por um conjunto de argumentos que se apóiam nos elementos constitutivos do negócio jurídico.

Para o melhor entendimento deste tópico, é conveniente explicitar os conceitos jurídicos de obrigação e contrato, bem como a relação entre ambos.

Vejamos inicialmente a definição de obrigação, segundo Beviláqua citado por Venosa ${ }^{13}$ (p.27):

Obrigação é a relação transitória de direito, que nos constrange a dar, fazer ou não fazer alguma coisa, em regra economicamente apreciável, em proveito de alguém que, por ato nosso ou de alguém conosco juridicamente relacionado, ou em virtude de lei, adquiriu o direito de exigir de nós essa ação ou omissão.

Fala-se, correntemente, em "estrutura da obrigação" e atribuem-se-lhe três elementos: sujeitos, objeto e vínculo jurídico.

Os sujeitos classificam-se em ativo (credor) e passivo (devedor), facilmente identificáveis, para os propósitos deste texto, como paciente e médico.

O objeto é classificado em imediato e mediato $^{13}$ (p. 40). O objeto imediato corresponde ao tipo de prestação: dar, fazer ou não fazer; no caso em pauta, trata-se de obrigação de fazer (uma cirurgia). O objeto mediato corresponde ao bem material de que se constitui a prestação: em nosso caso, por exemplo, rinoplastia, mamoplastia, etc.

Um conceito importantíssimo a ser ventilado neste ponto é o de que a prestação/objeto deve ser física e juridicamente possível(2). A possibilidade ou impossibilidade jurídica coincide com a licitude ou ilicitude do ato. Como os atos cirúrgicos, em regra, são lícitos, a questão não é relevante para este texto ${ }^{(3)}$.

A importância acima apontada para o conceito esteia-se, portanto, na possibilidade/ impossibilidade física, podendo-se adiantar, neste momento: é possível exigir resultado previamente determinado em um procedimento eivado de álea? Voltaremos ao argumento em outra parte deste texto.

O terceiro elemento da estrutura da obrigação acima anunciado, "vínculo jurídico", não apresenta maior interesse para esta discussão.

Ao contrário, a fonte ${ }^{(4)}$ das obrigações é relevante.

Segundo Rodrigues ${ }^{6}$ (p. 10), as obrigações podem ser classificadas em três grupos quanto à fonte: 1) derivadas diretamente da vontade humana (contratos e manifestações unilaterais de vontade); 2) derivadas de atos ilícitos (culposos e dolosos); 3) derivadas diretamente da lei.

Para os propósitos deste texto interessam os contratos (manifestação bilateral de vontade) e os atos ilícitos.

Quanto aos atos ilícitos, na verdade, não há

\footnotetext{
(2)Exigência inclusive constante de lei: artigo 166, Il do Código Civil.

(3) Exemplo típico de ato médico ilícito e conseqüente obrigação juridicamente impossível é o aborto sem que se apresentem as duas hipóteses permissivas do artigo 128 do Código Penal: risco de vida da gestante e gestação resultado de estupro.

(4) Ou seja, como nascem as obrigações.
} 
Pittelli SD. A prestação obrigacional do cirurgião plástico como obrigação de resultado.

muito que falar, merecendo referência apenas como introdução ao tema: são classicamente conhecidos como fonte de obrigações para o médico quando da ocorrência do assim denominado "erro médico". $\mathrm{O}$ direito, tradicionalmente, considerava a natureza da relação médico paciente como sendo "extracontratual", o que equivale a dizer que a única fonte de obrigação pelo ato médico praticado seria o ato ilícito.

Hodiernamente, entretanto, classifica-se a relação médico paciente em contratual quando o tratamento é eletivo, permanecendo a natureza extra-contratual nos casos de urgência/emergência. É ponto pacífico, entretanto, que essa diferenciação apresenta utilidade exclusivamente nos casos em que a prestação obrigacional do médico for considerada como sendo de resultado ${ }^{14,19}$.

Como essa concepção se aplica ao caso das cirurgias plásticas estéticas, impõe-se apresentar alguns conceitos relativos ao contrato.

Uma definição simples desse instituto jurídico é que se trata de uma "declaração de vontade destinada a produzir efeitos jurídicos"13 (p.393). O importante nessa definição é a relevância das vontades dos contratantes para a conformação do contrato.

Segundo o mesmo autor, mais do que um elemento do negócio jurídico (gênero do qual o contrato é uma espécie) "é um pressuposto do próprio negócio, que ora interferirá em sua validade, ora em sua eficácia, quando não na própria existência, se a vontade não houver sequer existido". Mais uma vez queremos chamar a atenção para a inafastável importância da manifestação da vontade das partes contratantes para que qualquer elemento do contrato possa ser aceito como idôneo e válido ou, em outras palavras, para obrigar as partes nos termos dos conceitos da teoria das obrigações anteriormente expostos. Evidentemente, ambas as vontades devem ser convergentes, ou, mais uma vez no dizer de Venosa13 (p.465), "O contrato constitui um ponto de encontro de vontades".

Assim como as obrigações, o contrato também possui um objeto imediato e um objeto mediato.

O primeiro é constituído exatamente pela obrigação que gera (dar, fazer ou não fazer) e o segundo pela prestação contida nessa obrigação (mamoplastia, rinoplastia, etc. $)^{13}$ (p.469). Em face desta última característica, aplicam-se ao objeto do contrato as mesmas exigências e/ou restrições apresentadas quando falávamos das obrigações: devem ser possíveis tanto física quanto juridicamente.

Como vemos, dispensando a exigência de precisão de termos e conceitos, para os propósitos deste texto podemos nos referir a contrato e obrigação como institutos e conceitos indiferenciáveis.

Antes de terminarmos estas breves noções jurídicas, resta trazer a lume mais duas questões.

A primeira delas vem a ser uma característica relevante, tanto dos contratos quanto das obrigações: o conteúdo econômico.

Quanto às obrigações, a definição acima transcrita já indica essa circunstância. A identidade entre os dois institutos já permite supor que o mesmo ocorra com os contratos, fato efetivamente confirmado pela doutrina ${ }^{13}\left(p .471^{*}\right)^{(5)}$.

A segunda remete-nos à dicotomia obrigação de meio e de resultado.

Ao diferenciar os dois tipos, Venosa ${ }^{13}$ (p.81), assim se manifesta:

A idéia fundamental reside na noção de saber e de examinar o que o devedor prometeu e o que o credor pode razoavelmente esperar.

Ora o devedor compromete-se, por exemplo, a entregar determinada mercadoria (há um resultado pretendido); ora o devedor compromete-se somente a empregar os meios apropriados de seu mister, para determinada atividade, o que permitirá ao credor "esperar" um resultado satisfatório, podendo ocorrer que esse bom resultado não seja alcançado.

Há duas questões relevantes a ressaltar que exsurgem desse texto.

A primeira delas é, mais uma vez, a importância da vontade como instituidora de todos os elementos que dão forma ao contrato concreto.

A segunda é uma antecipação da discussão que faremos em tópico próprio: não sabemos se ao se expressar como o fez, o autor teve a intenção de produzir o efeito que ora apontaremos, mas ressaltamos que entendemos ser de suma significância o fato de que é aquilo a que o devedor se compromete "o que permitirá ao credor esperar ...".

Ou seja, aquilo que o credor pode razoavelmente esperar depende daquilo que o devedor prometer, e não o contrário.

Um último ponto vem a ser, na realidade, uma constatação. É fato que a lei não define o

(5) Para adequada compreensão do que significa a expressão "conteúdo econômico" com referência a uma obrigação de fazer constituída por formas de tratamentos médicos, sugerimos a leitura deste autor, pg. 471/472. 
tipo de responsabilidade (entenda-se: tipo de obrigação) (Sebastião ${ }^{15}$ (p.65) e Venosa ${ }^{13}$ (p.82) e que a distinção resulta da exegese que a Justiça faz de cada "fato ocorrido" 15 , com vistas às prévias intenções das partes.

Terminadas essas brevíssimas considerações relativas à teoria das obrigações e dos contratos, passamos então à análise dos argumentos que denominamos de estritamente jurídicos, porque baseados nos princípios teóricos que acabamos de apresentar.

Tais argumentos podem ser divididos em três grupos, segundo o elemento do contrato em que se apóiam: sujeito passivo (médico), sujeito ativo (paciente) e o objeto.

A seguir faremos transcrições de textos que exemplificam cada um dos tipos, sublinhando, em cada texto, o elemento que corresponde ao núcleo do argumento. Começaremos por citações relativas aos sujeitos da relação contratual, inicialmente os passivos (médicos), a seguir os ativos (pacientes).

Stoco $^{16}$, (p. 548), alude ao que seria conteúdo da declaração de vontade do sujeito passivo da relação contratual, o médico.

O que importa considerar é que o profissional na área da cirurgia plástica, nos dias atuais, promete um determinado resultado (aliás, essa é a sua atividade fim), prevendo, inclusive, com detalhes, esse novo resultado estético procurado. Alguns utilizam-se mesmo de programas de computador que projetam a nova imagem (nariz, boca, olhos, seios, nádegas, etc.), através de montagem, escolhida na tela do computador ou na impressora, para que o cliente decida.

Matielo"17, (p. 56): "A obrigação de resultado deriva, então, da expectativa criada pelo profissional no sentido de que a aparência irá sofrer alterações positivas após a intervenção, destinando-se esta, tão somente ao propósito embelezador".

Pereira $^{1}$ (p. 157):

Com a cirurgia estética, o cliente tem em vista corrigir uma imperfeição ou melhorar a aparência. Ele não é um doente, que procura tratamento, e o médico não se engaja na sua cura. O profissional está empenhado em proporcionar-lhe o resultado pretendido, e se não tem condições de consegui-lo, não deve efetuar a intervenção.

Magalhães $^{18}$, (p. 91) assim se expressa, aludindo ao ponto de vista do paciente (sujeito ativo):

Quando alguém, que está muito bem de saúde, procura um médico somente para melhorar algum aspecto seu, que considera desagradável, quer exatamente esse resultado, não apenas que aquele profissional desempenhe seu trabalho com diligência e conhecimento científico, caso contrário, não adiantaria arriscar-se e gastar dinheiro por nada. Em outras palavras, ninguém se submete a uma operação plástica se não for obter um_determinado resultado, isto é, a melhoria de uma situação que pode ser, até aquele momento, motivo de tristeza.

\section{Rodrigues ${ }^{19}$ (p. 249):}

Enquanto naquele caso trata-se de pessoa doente que busca uma cura, no caso da cirurgia plástica o paciente é pessoa sadia que almeja remediar uma situação desagradável, mas não doentia. Por conseguinte, 0 que o paciente busca é um fim em si mesmo, tal como uma nova conformação do nariz, a supressão de rugas, a remodelação de pernas, seios, queixo, etc. De modo que o paciente espera do cirurgião, não que ele se empenhe em conseguir um resultado, mas que obtenha o resultado em si.

\section{Gonçalves $^{20}$ (p. 366):}

Quanto aos cirurgiões plásticos, a situação é outra. A obrigação que assumem é de 'resultado'. Os pacientes, na maioria dos casos de cirurgia estética, não se encontram doentes, mas pretendem corrigir um defeito, um problema estético. Interessa-Ihes precipuamente o resultado.

O que salta à vista em ambos os tipos de argumentos é a desconsideração do necessário acordo de vontades entre as partes: atribui-se ao médico uma intenção ou disposição sem que ela tenha sido consultado se se dispõe a tal e atribuise à expectativa do paciente o poder de definir a obrigação do médico, ignorando, aqui também, a vontade do profissional.

Abordando inicialmente as afirmações relativas ao médico, a contra-argumentação deve necessariamente começar pela óbvia invocação da importância da manifestação da vontade na conformação do contrato.

Conforme se constata dos elementos conceituais acima expostos, essa condição deve ser apreciada em cada caso concreto, verificando exatamente o que foi acordado pelas partes e, no caso específico, exatamente o que foi prometido pelo cirurgião.

Sob essa perspectiva, entendemos ser indevida a postura de admitir uma manifestação genérica de vontade que se aplicaria a terceiros, ainda mais sendo tais terceiros constituídos por toda uma classe de profissionais. 
Pittelli SD. A prestação obrigacional do cirurgião plástico como obrigação de resultado.

A alegada expectativa do paciente, por sua vez, ou, dito de outra forma, o fato de pretender um resultado determinado, em princípio, como tivemos oportunidade de apontar acima, deve depender do que o cirurgião efetivamente prometeu, como em qualquer relação contratual. Nesse sentido, podemos afirmar que não há nenhuma diferença entre a cirurgia plástica estética e todas as demais especialidades médicas: em qualquer campo da atividade médica, se o profissional prometer determinado resultado, estará vinculado à sua promessa, mas só nessa circunstância.

Além desses dois argumentos jurídicos, há um terceiro, de ordem factual, que envolve os conceitos expressos nestas transcrições.

É lugar comum dizer que o paciente que procura a cirurgia plástica, "quer exatamente esse resultado"18 ou que o paciente "busca um fim em si mesmo"19.

Ora, com a possível exceção de pacientes em fase terminal, todo paciente que procura o médico para tratar-se também quer um resultado determinado: a cura. Ninguém em sã consciência procura o médico para ficar "meio bom". Nem por isso a obrigação dos médicos nesses casos passa a ser de resultado.

Por outro lado, a pretensão de cura também é "um fim em si mesmo"(6) tanto quanto o paciente do cirurgião plástico quer obter uma melhora na sua aparência, o paciente comum quer obter melhora na saúde e restituição de sua vida ao nível de bem estar e conforto anterior à doença. As duas categorias de tratamento são transitivas e não intransitivas como pretende Rodrigues ${ }^{19}$.

Vejamos agora o terceiro grupo de argumentos jurídicos, relativos ao objeto do contrato. Divisamos quatro tipos de argumentos nesse grupo.

Rosário ${ }^{21}$ (p. 87), registra que para que ocorra obrigação de resultado é necessário um contrato que possua um fim (objeto) socioeconômico e que este, no caso das cirurgias estéticas, seria exatamente o fato do resultado pretendido.

Conforme se constata da definição de obrigação exposta acima, o componente socioeconômico é característico do instituto ${ }^{13}$ ( $p$. 471), incidindo em todas as relações contratuais. Assim sendo, não conseguimos entender em que sentido o contrato entre cirurgião plástico e paciente seria diferente de todos os demais contratos entre médicos e pacientes e com que fundamento esse critério diferenciaria a obrigação do cirurgião plástico da obrigação dos demais médicos.

Uma segunda ordem de idéias no âmbito do objeto do contrato esteia-se na exigibilidade de possibilidade física do objeto. Ao apresentar o conceito acima, fizemos a pergunta: é possível exigir resultado previamente determinado em um procedimento eivado de álea? Se admitirmos como sendo negativa a resposta, a liceidade da obrigação implicará em que necessariamente a obrigação seja de meio, pois, raciocinando a contrario sensu, não se pode exigir do médico (não é lícito exigir dele) aquilo que ele não pode, fisicamente, garantir.

Um terceiro argumento relacionado ao objeto do contrato é representado pela afirmação de que o resultado, na cirurgia plástica estética depende exclusivamente do prestador. Segundo Sebastião $^{15}$ (p. 65), será de resultado a obrigação cujo fim depender apenas da conduta do contratado. Ao tratar, em outro local do texto, especificamente da cirurgia plástica, consigna a esta a natureza de obrigação de resultado, donde se conclui que para esse autor o resultado nesse tipo de cirurgia depende exclusivamente do cirurgião. O equívoco é imenso. Além de ser influenciável por fatores genéticos, como no caso da tendência para formação de cicatrizes hipertróficas, quelóide e hiperpigmentação, os resultados dos procedimentos estéticos dependem notoriamente do comportamento do paciente, cabendo a estes, dependendo do caso, medidas tais como não tomar sol, não praticar esforços (e/ou guardar repouso), não fumar, tomar medicação prescrita, usar sutiã especial em casos de cirurgia de mamas, etc. Além de todos esses elementos, fatores completamente alheios mesmo à vontade do paciente podem influir, tal como a instalação per ou pós-operatória imediata de quadros que diminuam a resistência imunológica e possibilitem infecção do leito cirúrgico: desde uma simples gripe até moléstias bem mais graves como herpes zoster, para não falar de depressão.

O quarto e último argumento relativo ao objeto é que o risco do procedimento é criado pelo cirurgião.

Essa afirmação leva a discussão para o campo da responsabilidade objetiva, negada pela quase totalidade dos defensores da obrigação de resultado. O assunto, pela complexidade, merece um texto próprio e não será tratado aqui. Neste ponto, restringiremos a discussão aos limites do objeto deste artigo, a não ser por breves comentários

\footnotetext{
(6) Mesmo nos paciente terminais, o bem estar físico, psicológico e espiritual a que se propõe propiciar-Ihe o médico paliativista não deixa de ser "um fim em si mesmo".
} 
Pittelli SD. A prestação obrigacional do cirurgião plástico como obrigação de resultado.

abaixo consignados.

Podemos entender a afirmação acima de dois modos.

O primeiro é que o cirurgião criaria todo o risco com sua atitude, ou seja, não haveria nenhum grau de risco intrínseco ao procedimento. Essa discussão foi iniciada na segunda parte deste artigo, quando foi demonstrado o caráter de imponderabilidade dos mecanismos biológicos envolvidos nos procedimentos plásticos, sobretudo no fenômeno da cicatrização. Nesse sentido, a já transcrita afirmação de Aguiar Jr..$^{9,10}$ segundo quem a obrigação do cirurgião plástico "continua sendo sempre a obrigação de prestar um serviço que traz consigo o risco". Além disso, há todas as vicissitudes dependentes do paciente ou por qualquer modo alheias à vontade do profissional, que acabamos de citar.

O segundo modo de entendimento seria que a decisão de submeter o paciente a risco seria do médico e ele obteria vantagens econômicas dessa decisão, devendo, portanto, pagar pelas conseqüências indesejáveis de seus atos. Trata-se de acabada assunção da teoria do risco criado, que tantos cultores da obrigação de resultado negam seja aplicável à cirurgia plástica e mesmo a toda a medicina.

Como registramos acima, a complexidade e natureza do assunto extrapola os limites deste texto, mas algumas considerações são indispensáveis.

Dá-se que a teoria do risco, segundo nosso entendimento, caracteriza-se por dois elementos: a submissão ao risco independe do consentimento do lesado e o risco não pode ser afastado com medidas simples, singelas.

Tomemos como exemplo um possível acidente nuclear na Usina de Angra dos Reis. Todos os moradores da cidade de São Paulo estarão, em tese, sujeitos a dano. Nenhum deles foi consultado sobre a construção do complexo e a medida para evitar a possibilidade de risco não é singela: seria, por exemplo, mudar da cidade para uma distância segura (que não é pequena). Além de não ser simples em termos da vida das pessoas, é inaplicável a toda a população sob risco, até porque implicaria em acabar com uma metrópole de vários milhões de habitantes.

Nenhum dos dois elementos está presente na situação fática relativa à cirurgia plástica: o paciente só se submete ao risco se quiser e a recusa é uma decisão singela; sua vida não mudará significativamente em função da decisão pela negativa. Giostri ${ }^{5}$, ao falar sobre o papel ativo do credor no contrato com o médico (referindose às obrigações de resultado), dispõe que "o credor aceitou certos riscos inerentes à atividade daquele".

Por último, entendemos que há uma única e restrita situação em que o cirurgião plástico poderia eventualmente ser responsabilizado pelo simples mau resultado: quando o resultado estético insatisfatório fosse atribuível exclusivamente a ele, sem que se pudesse fazer qualquer apelo a elementos aleatórios. Costumamos comparar tal situação à de um mestre de obras que, não obstante toda a técnica disponível, levantasse uma parede torta ou que não fosse reta, por exemplo, pelo simples fato de não saber assentar tijolos ou usar corretamente o fio de prumo, etc.

Registramos, entretanto, que a situação, ao contrário do que pode parecer, não é exclusiva do cirurgião plástico: imaginemos um gastrocirurgião tão inábil que suas suturas término-terminais de alça resultassem em estenose ou deiscência numa freqüência muito maior do que o comum. Ele estaria "pecando" pelo simples resultado, tanto quanto o cirurgião plástico que obtivesse como resultado de uma mamoplastia redutora, mamas notoriamente assimétricas em volume, pela inábil retirada de quantidades muito diferentes de tecido.

Concluímos que a questão é muito mais complexa do que o modo como é apresentada e discutida e que também no âmbito da cirurgia plástica (assim como nos demais campos da Medicina) é fundamental não confundir resultados devidos à álea com resultados devidos diretamente à incompetência ou mau treinamento do cirurgião.

\section{CONCLUSÃO}

A concepção sobre a natureza da obrigação do cirurgião plástico remonta à idade média quando se ancorava na intocabilidade e sacralidade do corpo humano, por parte de qualquer cirurgião. Remanescente deste preconceito, a concepção atual apóia-se em dois tipos de conceitos errôneos: um relativo à álea, constituído pela confusão entre o processo biológico envolvido no ato médico e o resultado final pretendido, denominado "cura", associando-se a álea exclusivamente a este e não a todo o processo e outro caracterizado pela aplicação equivocada de conceitos intrínsecos aos institutos jurídicos das obrigações e/ou contratos, desrespeitando o princípio básico destes institutos, que vem a ser a manifestação de vontade das partes. 
Pittelli SD. The legal obligation of the plastic surgeon as a result obligation: systematization and critical analysis of the fundamentals. Saúde, Ética \& Justiça. 2011;16(2):93-102.

ABSTRACT: The author addresses and systematizes arguments in favor of assigning to the plastic surgeon's legal obligation a nature of obligation of results, (as opposed to obligation of means). Three groups of fundamentals are identified and discussed: historic, referred to the incidence of the alea and legal.

KEYWORDS: Plastic surgery; Damage liability; latrogenic disease.

\section{REFERÊNCIAS}

1. Pereira CMS. Responsabilidade civil de acordo com a constituição de 1988. 6a ed. Rio de Janeiro: Forense; 1995.

2. Dias JA. Da responsabilidade civil. Rio de Janeiro: Forense; 1944.

3. Castro JM. Responsabilidade civil do médico. São Paulo: Método; 2005.

4. outo Filho AF, Souza AP. Instituições de direito médico. Rio de Janeiro: Forense; 2004.

5. Giostri HT. Erro médico à luz da jurisprudência comentada. 2a ed. Curitiba: Juruá Ed.; 2004.

6. Rodrigues S. Direito civil - parte geral das obrigações. 29a ed. São Paulo: Saraiva; 2001. v. 2.

7. Kfouri Neto M. Responsabilidade civil do médico. 6a ed. São Paulo: Revista dos Tribunais; 2007.

8. Andorno LO. La responsabilidad civil médica. Ajuris. 1993;59:224-35.

9. Aguiar Junior RR. Responsabilidade civil do médico. In: Teixeira SF, coordenador. Direito e medicina aspectos jurídicos da medicina. Belo Horizonte: Livraria Del Rey Editora; 2000. p.133.

10. Aguiar Junior RR. Responsabilidade civil do médico. RT. 1995;718:33-53.

11. Forster NJ. Cirurgia plástica estética: obrigação de resultado ou obrigação de meios? RT.
1997;738:83-9.

12. Ometto RTV. Responsabilidade civil do médico cirurgião. Capivari: Unimed Gráf. Ed.; 2004.

13. Venosa SS. Direito Civil. 5a ed. São Paulo: Atlas; 2005.

14. Pittelli SD. Responsabilidade Civil do Cirurgião Plástico: condições em que se dá a aplicação dos fundamentos da responsabilidade objetiva [tese]. São Paulo: Faculdade de Medicina da Universidade de São Paulo; 2006.

15. Sebastião J. Responsabilidade médica - civil, criminal e ética. 2a ed. Belo Horizonte: Livraria Del Rey Ed.; 2001.

16. Stoco R. Tratado de responsabilidade civil. 6a ed. São Paulo: Revista dos Tribunais; 2004.

17. Matielo FZ. Responsabilidade civil do médico. Porto Alegre: Sagra Luzzato; 1998.

18. Magalhães TAL. $O$ dano estético. Responsabilidade Civil. 2a ed. São Paulo: Revista dos Tribunais; 1999.

19. Rodrigues S. Direito civil - responsabilidade civil. 14a ed. São Paulo: Saraiva; 1995. v. 4.

20. Gonçalves CR. Responsabilidade civil. 8a ed. São Paulo: Saraiva; 2003.

21. Rosário GCM. Responsabilidade civil na cirurgia plástica. Rio de Janeiro: Ed. Lumen Juris; 2004.

Recebido em: 31/10/11

Aprovado em: 08/12/11 